\title{
A Novel Approach for Iron Deficiency Anaemia with Liposomal Iron: Concept to Clinic
}

\author{
Manish Maladkar*, Srividya Sankar, Ashok Yadav \\ Scientific Department, Aristo Pharmaceuticals Private Ltd., Mumbai, India \\ Email: ${ }^{*}$ scientific@aristopharma.org
}

How to cite this paper: Maladkar, M. Sankar, S. and Yadav, A. (2020) A Novel Approach for Iron Deficiency Anaemia with Liposomal Iron: Concept to Clinic. Journal of Biosciences and Medicines, 8, $27-41$.

https://doi.org/10.4236/jbm.2020.89003

Received: May 7, 2020

Accepted: September 6, 2020

Published: September 9, 2020

Copyright $\odot 2020$ by author(s) and Scientific Research Publishing Inc. This work is licensed under the Creative Commons Attribution International License (CC BY 4.0).

http://creativecommons.org/licenses/by/4.0/

\begin{abstract}
Iron deficiency anaemia is the most common nutritional deficiency disorder, contributing to 50 percent of all the anaemias in the world. Dietary changes alone are insufficient for the correction and management of iron deficiency anaemia. Hence, iron supplementation is necessary. Conventional oral iron therapy is limited in many patients because of dose dependent side effects, insufficient absorption, lack of compliance and limitation in various inflammatory conditions. Liposomal iron is a technologically designed, innovative form of iron which due to its differential delivery system ensures higher absorption and bioavailability, greater tolerability and least gastro-intestinal side effects unlike conventional oral iron preparations. This review provides a critical discussion and a comprehensive view based on the author's review of the medical literature concerning the technology of liposomal iron preparation, mechanism of its absorption, its advantage over conventional iron preparations and clinical evidence on its usage in iron deficient states in pregnancy and certain inflammatory conditions.
\end{abstract}

\section{Keywords}

Liposomal Iron, Iron Deficiency, Anaemia, Microencapsulation, Micronisation, Pregnancy, Inflammation, Chronic Kidney Disease

\section{Introduction}

Iron is amongst the most essential mineral required for human life and is abundantly available in the earth's crust. From ancient times, man has recognized the importance of iron in health and disease. Its early medicinal uses were explored and identified by Egyptians, Hindus, Greeks, and Romans [1]. Iron is vital for several bodily functions including haemoglobin synthesis, transport of oxygen throughout the body and catalytic activity of various enzymes. In foetus and in- 
fants, it is vital for the development of brain, and therefore cognitive functions in developing stages of life [2].

For many years, nutritional interest in iron mainly involved its role in haemoglobin synthesis and oxygen transport in the body. However, today low iron intake and/or bioavailability are attributed for most anaemia in developing countries. As per World Health Organization (WHO) estimates, approximately two billion people are anaemic worldwide and around $50 \%$ of all anaemias are attributed to iron deficiency [3]. It occurs at all stages of the life cycle but is more prevalent in pregnant women and young children [4]. The liposomal form of iron has emerged as a novel concept in the management of iron deficiency anaemia. In this review, we discuss in detail about the role of liposomal iron in the management of iron deficiency anaemia (IDA).

\section{Iron Physiology}

Iron is mainly distributed in two compartments in the body. The functional compartment includes a number of compounds like haemoglobin, myoglobin, transferrin and enzymes, and others which require iron as a cofactor or a prosthetic (ion or haem) group. The second is a storage compartment, which includes ferritin and haemosiderin constituting the body's mineral reserves [2]. The body iron content of a normal $70 \mathrm{~kg}$ individual is around $50 \mathrm{mg} / \mathrm{kg}(3.5-4 \mathrm{~g}$ in women, and $4-5 \mathrm{~g}$ in men). Iron is majorly distributed as haemoglobin (65\%, $2300 \mathrm{mg}$ ), myoglobin and enzymes (15\%), iron stores (20\%), and transferrin bound $(0.1 \%-0.2 \%)$ [5].

A normal diet may contain $6 \mathrm{mg}$ iron per 1000 calories. With a daily intake of $15-20 \mathrm{mg}$ of iron, only $1-2 \mathrm{mg} /$ day gets absorbed in the duodenum and the first part of the jejunum. There are two forms of iron which gets absorbed, viz. haem (10\%) and non-haem (90\% ionic). Haem iron is found in foods of animal origin (e.g. red meat, chicken and fish) in the form of haemoglobin or myoglobin. Non-haem (inorganic) iron is mainly found in foods of plant origin, cereals, and some foods of animal origin such as milk and eggs. Absorption of haem iron $(15 \%-20 \%)$ is better than non-haem iron (5\%). Haem iron is directly taken up by intestinal cells through a process called endocytosis, where haem-oxygenase (hox) breaks its ring to release ferrous iron $\left(\mathrm{Fe}^{2+}\right)[2]$.

Dietary non-haem or inorganic iron is usually found in Ferric form $\left(\mathrm{Fe}^{3+}\right)$. $\mathrm{Fe}^{3+}$ undergoes transformation to its soluble ferrous $\left(\mathrm{Fe}^{2+}\right)$ iron form at the apical edge of enterocyte with the help of ferric reductase enzyme (duodenal cytochrome B [Dcytb]), thereby allowing it to pass through the mucous membrane of the intestine. Non-haem iron is transported through enterocyte by divalent metal transporter 1 (DMT1), a membrane transport proteins. DMT1 is also responsible for the transport of other metallic ions such as zinc, copper and cobalt by means of a proton coupling mechanism. Absorption of non-haem iron is strongly influenced by dietary factors, such as meat or ascorbic acid (vitamin C), which improve its bioavailability. However, diet containing calcium (dairy 
products), tannins (tea) or phytates (fibre-rich diets) or concomitant administration of medicines such as tetracycline, proton pump inhibitors and antacids can reduce the iron absorption [5] [6].

In the enterocyte, a small portion of iron is stored in the form of ferritin and the rest is transported through the basolateral membrane into the bloodstream through $\mathrm{Fe}^{2+}$ transporter ferroportin 1 (Ireg-1), aided by the protein hephaestin, which transforms $\mathrm{Fe}^{2+}$ into $\mathrm{Fe}^{3+}$ [7]. Thus iron entered into the bloodstream is scavenged by transferrin, which maintains $\mathrm{Fe}^{3+}$ in a redox-inert state and delivers it into tissues. A significant proportion of this iron also gets stored in the macrophage as ferritin. The macrophages export $\mathrm{Fe}^{2+}$ from their plasma membrane via ferroportin, through a process involving reoxidation of $\mathrm{Fe}^{2+}$ to $\mathrm{Fe}^{3+}$ by ceruloplasmin, followed by the loading of $\mathrm{Fe}^{3+}$ to transferrin. Although, the total iron content of transferrin ( $\approx 3 \mathrm{mg}$ ) corresponds to less than $0.1 \%$ of body iron, it is highly dynamic and undergoes more than 10 times daily turnover to sustain erythropoiesis. The transferrin iron pool is replenished mostly by iron recycled from physiological haemolysis of senescent RBCs [8]. Normally iron is lost through sloughing of epithelial cells from the lining of the gastrointestinal (GI) tract (main pathway) and from the skin. However, these losses are estimated to be very limited ( $\approx 1-2 \mathrm{mg} /$ day). Iron losses through bleeding can be substantial and excessive menstrual blood loss is the most common cause of iron deficiency in women. Normal blood loss during menstruation is around $30 \mathrm{ml}$, which can be as high as $118 \mathrm{ml}$ in some women. Every $100 \mathrm{ml}$ of blood is estimated to contain around $40-50 \mathrm{mg}$ iron, and excessive menstrual blood loss can result in iron deficiency anaemia in young women with insufficient dietary iron intake [9].

\section{Hepcidin: The Key Regulator of Iron}

The concentration of iron in biological fluids is tightly regulated to maintain iron levels as needed and to avoid toxicity, as excess iron can lead to the generation of reactive oxygen species. Hepcidin is the major regulator of systemic iron homeostasis. It is a 25 amino-acid peptide hormone mainly expressed by the liver [10]. The expression of hepcidin is regulated by several physiological conditions, such as systemic iron levels, hypoxia, anaemia, erythropoiesis, infection and inflammation [11] [12] [13]. Hepcidin binds the cellular iron exporter, ferroportin (Fpn), inducing its internalization and degradation in hepatocytes, enterocytes, and macrophages, preventing iron transport to plasma and causing cellular retention of iron [14]. Due to decreased iron entry into plasma, there can be low transferrin saturation and less iron delivery to the developing erythroblast. In contrary, decreased expression of hepcidin can increase cell surface ferroportin and increase iron absorption [15] (Figure 1).

Dysregulation of hepcidin expression results in iron disorders. Inflammatory conditions trigger the expression of hepcidin which lowers intestinal iron absorption and stored iron release (mucosal block). Overexpression of hepcidin 


\section{Normal}

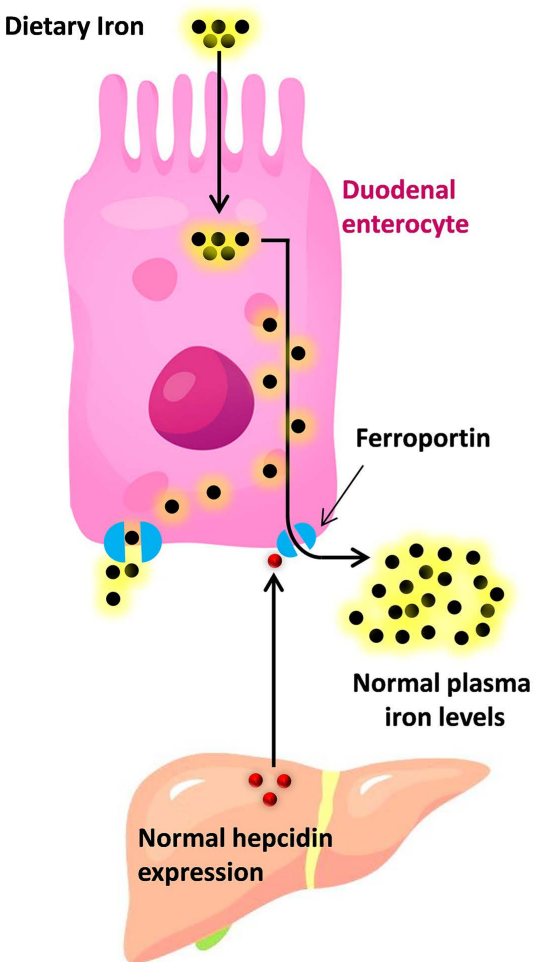

Inflammatory Condition

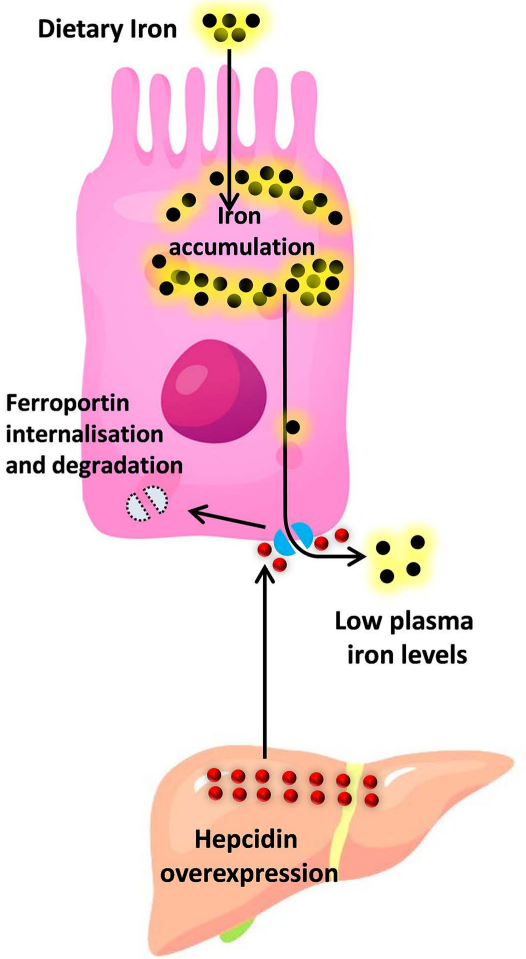

Iron Overload

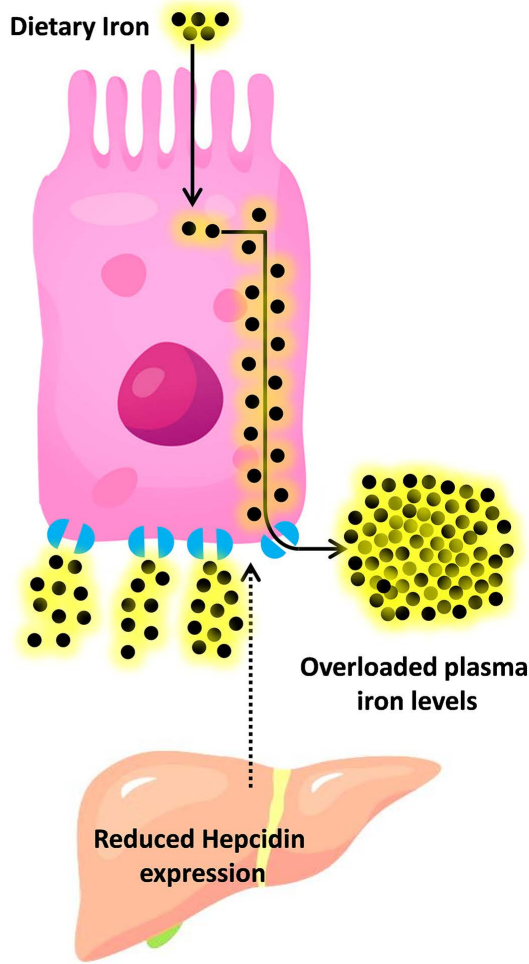

Figure 1. Hepcidin-mediated regulation of iron homeostasis. Source: De Domenico, et al. [15].

leads to the anaemia of chronic disease, while low hepcidin production results in hereditary haemochromatosis (HFE) with consequent iron accumulation in vital organs [15].

\section{Dietary Iron Recommendations for Indians}

In the Indian context, absorption of iron from a cereal-pulse based diet in adult male is $5 \%$ and is $8 \%$ in women who are expected to have better absorption due to iron deficient store. In infants of 6 - 12 months of age, iron absorption of 15\% is observed [16] (Table 1).

\section{Iron Deficiency Anaemia}

Anaemia is defined as the condition with a decreased number of RBCs in the blood, or RBCs have less than the normal amount of haemoglobin. Iron deficiency is the most significant and common cause of anaemia worldwide. Iron deficiency is defined as a condition with depletion of iron stores characterized by signs of a compromised supply of iron to tissues, including the erythrocytes. Iron deficiency can present with or without anaemia. Some functional changes may be evident in the absence of anaemia, but the most functional deficits manifest with the development of anaemia. IDA is a severe condition characterised by low levels of iron and the presence of microcytic hypochromic red cells [17].

The aetiology of IDA can be classified as: 
Table 1. RDA for iron in Indians [16].

\begin{tabular}{|c|c|c|c|c|c|}
\hline \multicolumn{2}{|c|}{ Group } & $\begin{array}{c}\text { Body weight } \\
\mathrm{Kg}\end{array}$ & $\begin{array}{c}\text { Requirement } \\
\mathrm{mcg} / \mathrm{kg} / \mathrm{d}\end{array}$ & $\begin{array}{l}\text { Absorption } \\
\text { assumed \% }\end{array}$ & $\begin{array}{l}\mathrm{RDA} \\
\mathrm{mg} / \mathrm{d}\end{array}$ \\
\hline \multicolumn{2}{|c|}{ Adult Men } & 60 & 14 & 5 & 17 \\
\hline \multicolumn{2}{|c|}{ Adult Women (NPNL) } & 55 & 30 & 8 & 21 \\
\hline \multicolumn{2}{|c|}{ Pregnant women } & 55 & 51 & 8 & 35 \\
\hline \multicolumn{2}{|c|}{ Lactating women $(0-6 \mathrm{~m})$} & 55 & 23 & 8 & 25 \\
\hline \multirow{2}{*}{ Infants } & $0-6 \mathrm{~m}$ & 5.4 & 46 & -- & -- \\
\hline & $6-12 m$ & 8.4 & 87 & 15 & 5 \\
\hline \multirow{3}{*}{ Children } & $1-3 \mathrm{yr}$ & 12.9 & 35 & 5 & 9 \\
\hline & $4-6 y r$ & 18.0 & 35 & 5 & 13 \\
\hline & $7-9 \mathrm{yr}$ & 25.1 & 31 & 5 & 16 \\
\hline \multicolumn{6}{|c|}{ Adolescents } \\
\hline Boy & $10-12 \mathrm{yr}$ & 34.3 & 31 & 5 & 21 \\
\hline Girl & $10-12 \mathrm{yr}$ & 35.0 & 38 & 5 & 27 \\
\hline Boy & $13-15 \mathrm{yr}$ & 47.6 & 34 & 5 & 32 \\
\hline Girl & $13-15 \mathrm{yr}$ & 46.6 & 29 & 5 & 27 \\
\hline Boy & $16-17 \mathrm{yr}$ & 55.4 & 25 & 5 & 28 \\
\hline Girl & $16-17 \mathrm{yr}$ & 52.1 & 25 & 5 & 26 \\
\hline
\end{tabular}

\subsection{Insufficient Iron Intake}

Iron intake insufficiency is more common in paediatric population, in children during growth years, infants who are weaned early to cow's milk or infant cereals (foods with low iron content), vegetarian diet or no intake of red meat and insufficient intake due to poverty.

\subsection{Abnormal Iron Loss (Chronic Bleeding)}

Commonly observed in adolescent and adult women with vaginal bleeding such as dysfunctional uterine bleeding or bleeding secondary to uterine disorders. Chronic conditions involving GI bleeding, such as erosive gastritis, bowel polyps, peptic ulcer, diverticulitis, benign tumours, intestinal cancer, inflammatory bowel diseases, angiodysplasia, haemorrhoids, hookworm infestation, obscure source.

\subsection{Increased Iron Requirement}

The main causes of increased demand for iron are pregnancy (second and third trimester), breastfeeding, and growth spurts in adolescence. 


\subsection{Impaired Iron Absorption or Acidification}

Iron malabsorption can be due to digestive disorders, celiac disease, inhibited hydrochloric acid secretion (use of proton pump inhibitors); Helicobacter pylori infection, atrophic gastritis, etc.

IDA is chronic, often asymptomatic and thus may be difficult to diagnose. Low oxygen perfusion of body tissues and decreased activity of iron-containing enzymes may lead to weakness, fatigue, poor concentration and non-specific symptoms like poor productivity. IDA is known to affect cognitive performance and to delay mental and motor development in children. Severe IDA in pregnancy can increase the risk of preterm labour, low neonatal weight and neonatal and maternal mortality.

\section{Management of IDA}

For the management of IDA, the objective of therapy is to normalise haemoglobin levels and replenish iron stores along with the correction of pathways causing loss or malabsorption of iron. Iron deficiency correction should begin with dietary recommendations (intake of iron rich foods). However, when dietary changes alone are insufficient to replenish iron stores and normalise haemoglobin levels, or in severe anaemia cases, iron supplement therapy should be initiated.

\subsection{Parenteral Iron Preparations}

Iron is administered intravenously in iron carbohydrate complexes formulations consisting of a mineral core, composed of polynuclear iron (III)-hydroxide surrounded by the carbohydrate ligand [18]. The ligand helps to stabilise the complex and also protect it against further polynuclearisation. Examples include iron sucrose, ferric carboxymaltose, sodium ferric gluconate in sucrose, for injection and various iron dextran formulations. The stable complexes of parenteral irons such as ferric carboxymaltose and iron dextran, after administration, are taken up by endocytosis by macrophages of the reticuloendothelial system (RES) [18]. However, the highly regulated process of iron release from carbohydrate complexes can be disrupted in less stable preparations. In this case, release of significant amounts of labile iron from the complex may cause saturation of transferrin and form significant amounts of non-transferrin bound iron (NTBI). This weakly bound $\mathrm{Fe}^{3+}$ may get deposited in an unregulated way inside the cells of endocrine system, the heart and the liver, where it can induce oxidative stress by catalysing lipid peroxidation and reactive oxygen species formation [19].

Parenteral iron preparations could be an alternative in patients who are unable to tolerate oral iron and are non-compliant or need rapid restoration of iron stores.

\subsection{Oral Iron Preparations}

Iron preparations providing more elemental iron per dose should be an ideal choice. Along with elemental iron content, the side effects of these preparations 
like nausea, vomiting, and abdominal pain should also be considered [20].

The administration of oral iron is a convenient, inexpensive, and effective means for IDA correction. There are a number of oral iron formulations available, and for the most part all are equally effective. Among the myriad preparations in the market, iron sulphate is the most frequently used, along with gluconate and fumarate as effective iron salts.

The dose of oral iron depends on patient's age, the estimated iron deficit, the rapidity with which it needs to be corrected and side effects. The recommended dose of oral iron in adults with iron deficiency anaemia is $100-200 \mathrm{mg}$ of elemental iron daily. There are a number of oral iron preparations available for the management of IDA. Their appropriate dosage is determined by the amount of elemental iron they deliver. As an example, a $325 \mathrm{mg}$ ferrous sulphate tablet contains $65 \mathrm{mg}$ of elemental iron per tablet; three tablets per day will provide $195 \mathrm{mg}$ of elemental iron, of which approximately $25 \mathrm{mg}$ is absorbed [21]. Thus, in order to meet the recommended daily dose of elemental iron; one may end up consuming higher doses of iron supplement which may cause GI side effects.

\subsection{Limitations of Conventional Oral Iron Preparations}

Conventional iron preparations usage is associated with various side effects like nausea, vomiting, flatulence, abdominal pain, diarrhoea, constipation, dyspepsia and black or tarry stools. These side effects have been the main concern with oral iron therapy. Up to 70 percent of patients who are on oral iron preparations (especially ferrous sulphate) report GI side effects [22]. Limitations associated with conventional iron salt led to emergence of different oral iron preparations like carbonyl iron, iron polymaltose complex, ferrous ascorbate, sodium feredetate and ferrous bisglycinate. However, efficacy and side effects were comparable between these conventional iron preparations when used for treating patients with IDA [23]. The impact of GI related side effects results in non-adherence in up to $50 \%$ of patients. Undesirable organoleptic attributes (metallic taste) also significantly contributes to the non-adherence of the therapy. These factors predispose patients to significant treatment failures and unnecessary follow-up investigations [22].

Oral iron therapy may not be effective for individuals with ongoing blood loss, inflammatory bowel disease or gastric bypass, chronic kidney disease (CKD), or those with substantial distress from the side effects of the same. During inflammation, macrophages produce high levels of IL-6, the pro-inflammatory cytokine that triggers the expression of hepcidin. This mechanistic increase in hepcidin levels reduces oral iron absorption in patients with concomitant inflammatory states like CKD, infection and cancer [24]. Hepcidin released into the circulation binds ferroportin, and the complex is internalized and degraded, in turn blocking iron export into the circulation (mucosal block). Moreover, higher or more frequent doses of iron supplement also raise circulating hepcidin levels and reduced subsequent fractional iron absorption [25]. This potential mechanism 
result in poor response to conventional oral iron preparations and supports the approach of switching to IV iron in patients with these conditions.

\section{Liposomal Iron: Breakthrough in the Management of IDA}

Liposomal iron is the breakthrough in the management of IDA, non-responsive to conventional oral iron preparations. Liposomes are effective drug carrier systems which have potential for target specific delivery of different therapeutic substances. Their biocompatibility, biodegradability and low toxicity make them suitable option for delivering drugs [26].

Liposomal iron, a new generation oral iron preparation of ferric pyrophosphate carried within a phospholipid and lecithin membrane, shows a high GI absorption and high bioavailability with lower incidence of side effects. It involves a sophisticated technology that uses liposomes as a carrier, where iron without coming in contact to GI mucosa gets directly absorbed in the intestine. The particle size of ferric pyrophosphate is reduced by the process known as Micronisation, which increases the solubility of iron. Processing into smaller particles increases the surface area of the molecule and thereby its dissolution rate. Further the micronised iron is encapsulated by a lipid bilayer membrane like biological membranes through Microencapsulation. The formed liposome thus has the structure of outer bilayer membrane and inner core containing the iron particles (Figure 2). Outer phospholipid bilayer prevents degradation of iron from enzymes in mouth and/or stomach, interaction with alkaline juices, bile salts, intestinal flora and protect from free radicals. Thus, liposomes prevent oxidation and degradation of the iron contents in the core and assists in targeted delivery [26] [27] [28].

Through "Trojan Horse-like" mechanism, the liposome is directly absorbed in the intestinal lumen by the microfold cells ( $\mathrm{M}$ cells) of the small intestine, which is the part of lymphatic system. Subsequently, the liposome is incorporated in macrophages by endocytosis and through the lymphatic system reaches hepatocytes. In hepatocytes, the liposome is opened by lysosomal enzymes, making the iron available for utilization [29].

\section{Advantages of Liposomal Iron}

\subsection{Better Bioavailability}

Liposomal iron facilitates quicker absorption and availability of iron in the body.

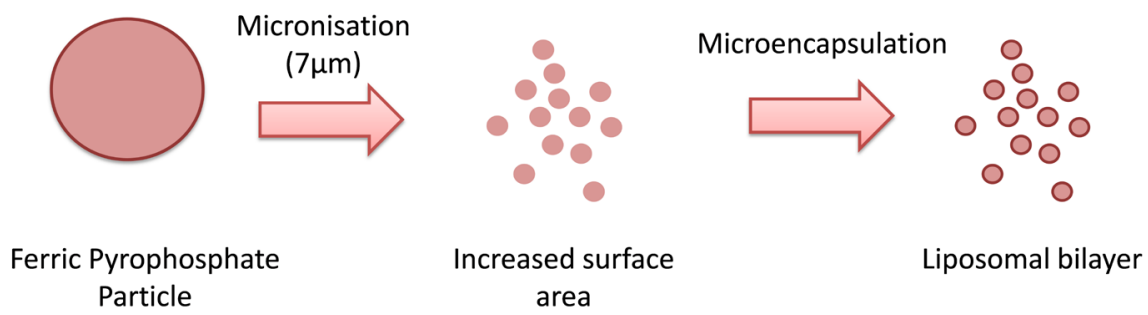

Figure 2. Technological representation of micronization and microencapsulation. 
Experimental studies have shown faster and significant improvement of serum iron and liver iron contents by liposomal iron as compared to conventional oral iron preparations [30].

An experimental study was done to evaluate the efficiency of iron absorption in four groups of rats. These Group received Liposomal iron (Lipofer ${ }^{\circledR}$ ), Ferrous sulphate, Ferric pyrophosphate free salt or control (carboxymethyl cellulose 1\%). The pharmacokinetic profile revealed that Lipofer ${ }^{\otimes}$ has the higher values of iron concentrations at any time points as compared to other salts [31] (Figure 3).

Liposomal iron (Lipofer ${ }^{\circledR}$ ) was 2.7 and 3.5 times more bioavailable than ferrous sulphate and plain ferric pyrophosphate, respectively [31] (Figure 4).

\subsection{Better Tolerability}

In a study, 30 post-menopausal females with iron deficiency anaemia (Haemoglobin, $\mathrm{Hb}<11.5 \mathrm{~g} / \mathrm{dL}$ ) who were already been treated with other iron supplements and experiencing side effects, were treated with liposomal iron supplement (microencapsulated iron pyrophosphate in liposomal form). After 8 weeks of supplementation there was a significant rise in haemoglobin and hematocrit levels and the treatment was well tolerated with statistically significant improvement in most of the side effects previously experienced by the patients [32] (Figure 5).

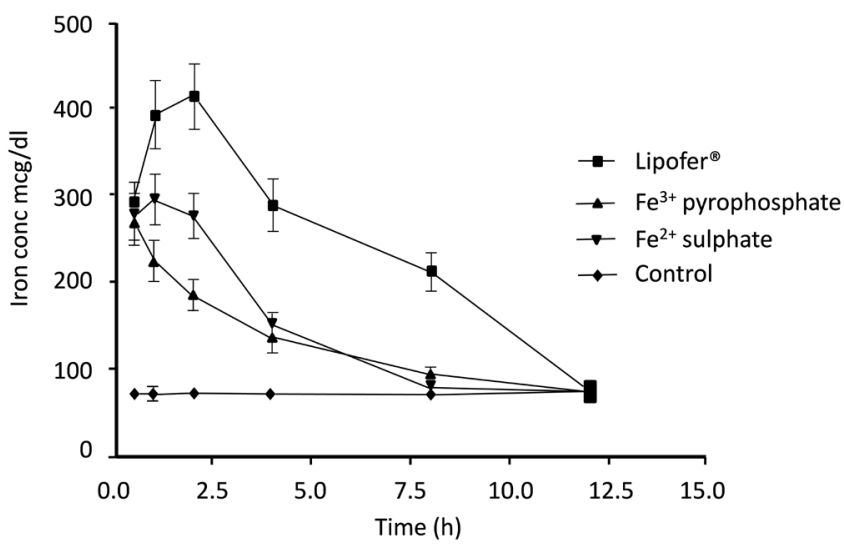

Figure 3. Iron concentration measured at different time points.

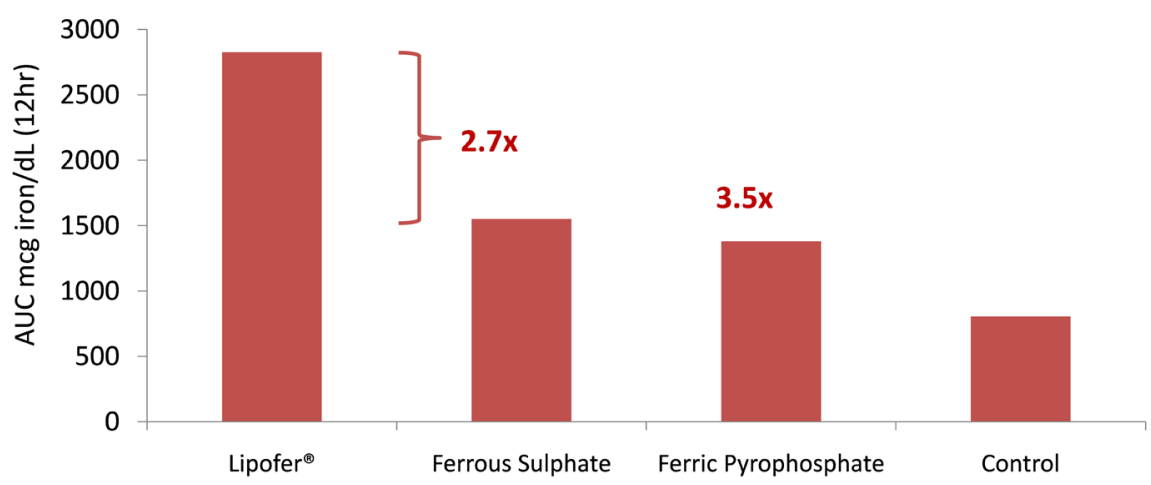

Figure 4. AUC values for different iron dosages. 


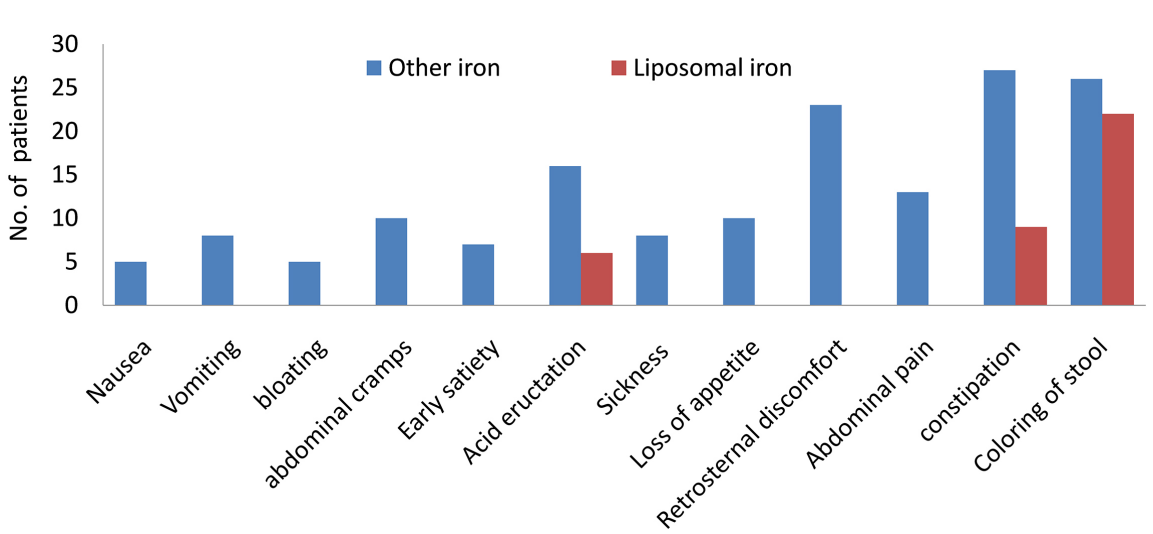

Figure 5. Side effect total score from previous iron and liposomal iron treatment.

\subsection{No Oxidative Adverse Effects}

The conventional iron can increase the oxidative damage evident by alteration in the malondialdehyde (MDA) and super-oxide dismutase (SOD) levels. Studies have confirmed that liposomal iron is associated with decreased MDA levels and increase in SOD levels. This may help in minimizing the oxidative damage otherwise seen with conventional iron preparations [30].

\subsection{No Interaction with Dietary Inhibitors}

The absorption of conventional non-haem iron could be restrained by factors like dietary inhibitors. Phytic acid in diets based on cereals and legumes has been shown to inhibit iron absorption in-vivo and in cell culture models. Iron preparation in liposomal form, due to technological processing advantage and different mechanism of absorption, offers a better iron delivery without being affected by dietary inhibitors [33].

\section{Evidence in Different Clinical Conditions}

\subsection{Pregnancy}

Parisi et al. conducted a study to compare the liposomal iron with ferrous sulphate in 80 non-anaemic pregnant women recruited at 11 to 13 weeks of gestation. They were randomised to one of the four treatment groups, controls ( $\mathrm{C} ; \mathrm{n}$ $=20)$ and groups supplemented with ferrous iron $30 \mathrm{mg}(\mathrm{SF} ; \mathrm{n}=20)$, liposomal iron $14 \mathrm{mg}(\mathrm{FF} 14 ; \mathrm{n}=20)$ and liposomal iron $28 \mathrm{mg}$ per day $(\mathrm{FF} 28 ; \mathrm{n}=20)$ up to 6 weeks post-partum. Both FF28 and FF14 groups showed significantly higher haemoglobin and ferritin concentrations compared with SF group and controls (Figure 6). Birth weight showed a trend to increase with supplementation, resulting in higher birth weight in the FF28 group compared with controls (3499 \pm $464.1 \mathrm{~g}$ and $3092 \pm 469.5 \mathrm{~g}$, respectively, $\mathrm{p}<0.01$ ) [34].

\subsection{Menstruating Women}

In a randomised, double-blind, placebo-controlled study of 16 weeks of duration, 122 iron deficient women were randomised to either microencapsulated 

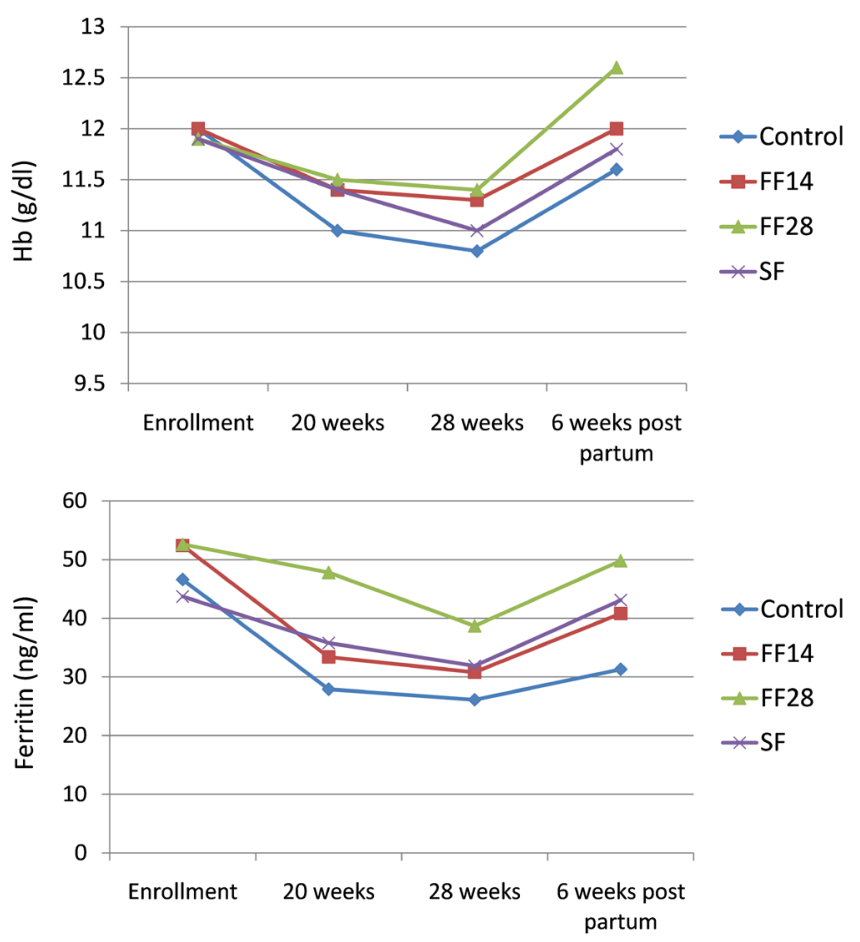

Figure 6. Liposomal iron group showed significant increase in $\mathrm{Hb}$ and ferritin levels compared to SF $(\mathrm{p}<0.01)$ and $\mathrm{C}(\mathrm{p}<0.05)$ groups at 28 weeks and in post-partum period.

iron pyrophosphate ( $\mathrm{F}$ group, $\mathrm{n}=64$ ) or placebo (P group, $\mathrm{n}=58$ ) as a supplement to usual diet. Microencapsulated iron pyrophosphate provided $18 \mathrm{mg}$ iron per day (100\% of the RDA). There was a significant $79 \%(\mathrm{p}<=0.001)$ increase in Ferritin levels in F group as compared to $\mathrm{P}$ group after 16 weeks (Figure 7). There was also significant increase in hematocrit $(\mathrm{p}=0.006), \mathrm{RDW}(\mathrm{p}=0.003)$ and $\mathrm{Hb}(\mathrm{p}<0.0001)$ levels [35].

\subsection{Inflammatory Conditions}

The inflammatory conditions render the absorption of conventional oral iron ineffective, due to increased hepcidin levels causing mucosal block. Hence, IV iron has shown a significant superiority to conventional oral iron in increasing Hb. However, Liposomal iron due to sophisticated technology overcomes mucosal block and ensures better bioavailability in such patients. Pisani et al. in a randomized trial showed that oral liposomal iron can be a safe and efficacious alternative to parenteral iron to correct anaemia in CKD patients. In this study, there was a similar increase in $\mathrm{Hb}$ in both liposomal iron group (30 mg/day) and IV iron group (ferrous gluconate $1000 \mathrm{mg} /$ day) with significantly low incidence of adverse event in the oral group (3.1 vs $34.5 \%, \mathrm{p}<0.001$ ) [36]. Also the results from studies done in refractory anaemia (myelodysplastic syndrome-MDS) indicate that oral liposomal iron may be as effective as IV iron in such patients [37]. Study with liposomal iron has shown to reduce inflammatory markers in correction of anaemia of chronic inflammatory disease of young women [38]. 


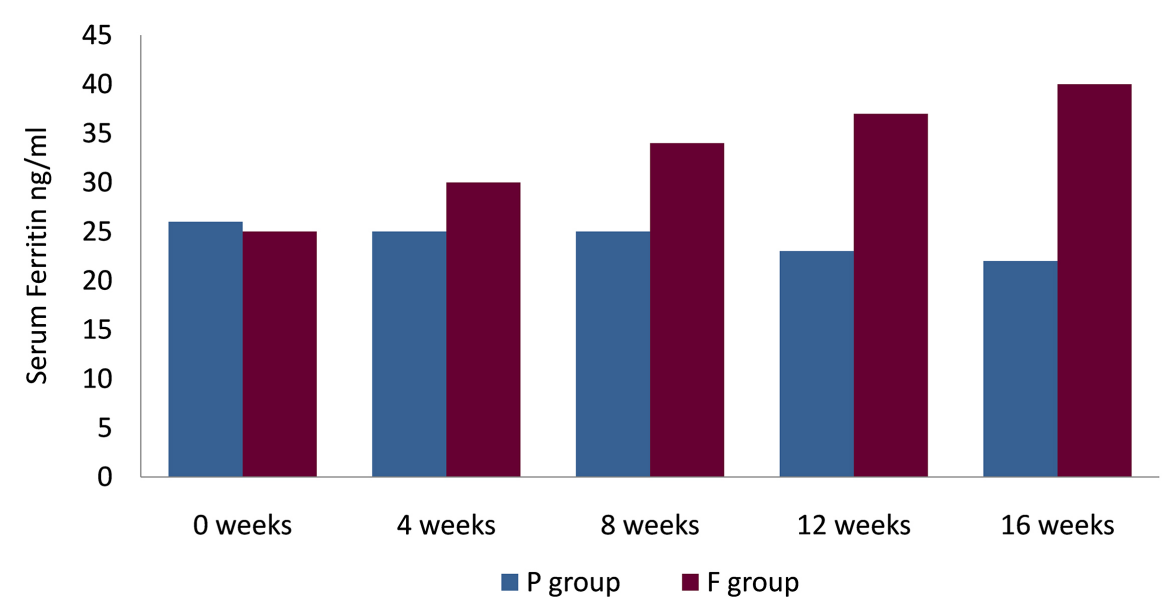

Figure 7. Increase in ferritin levels in F group as compared to P group.

\section{Conclusion}

Conventional iron preparations are often associated with various GI side effects resulting in non-adherence to the therapy by substantial number of patients. Liposomal iron, a new generation oral iron preparation, technologically engineered through process of micronisation and microencapsulation, helps to overcome the limitation associated with the conventional iron preparations. The technological advancement has translated the benefit into clinical outcomes as evidenced by multiple studies. Liposomal iron significantly increases $\mathrm{Hb}$, ferritin levels in pregnant as well as in women of reproductive potential and it is an effective and safe alternative to parenteral iron in chronic inflammatory conditions associated with IDA.

\section{Conflicts of Interest}

The authors declare no conflicts of interest regarding the publication of this paper.

\section{References}

[1] Abbaspour, N., Hurrell, R. and Kelishadi, R. (2014) Review on Iron and Its Importance for Human Health. Journal of Research in Medical Sciences, 19, 164-174.

[2] Barragán-Ibañeza, G., Santoyo-Sánchez, A. and Ramos-Peñafiel, C.O. (2016) Iron Deficiency Anaemia. Revista Médica del Hospital General de México, 79, 88-97. https://doi.org/10.1016/j.hgmx.2015.06.008

[3] World Health Organization and United Nations Children's Fund (2004) Focusing on Anaemia.

https://www.who.int/nutrition/publications/micronutrients/WHOandUNICEF_stat ement_anaemia/en/

[4] Ministry of Health and Family Welfare (2016) India Fact Sheet. National Family Health Survey 2015-16 (NFHS-4). http://rchiips.org/nfhs/pdf/NFHS4/India.pdf

[5] Andrews, N.C. (1999) Disorders of Iron Metabolism. The New England Journal of Medicine, 341, 1986-1995. https://doi.org/10.1056/NEJM199912233412607

[6] Mu Noz, M., García-Erce, J.A. and Remacha, Á.F. (2011) Disorders of Iron Meta- 
bolism. Part II: Iron Deficiency and Iron Overload. Journal of Clinical Pathology, 64, 287-296. https://doi.org/10.1136/jcp.2010.086991

[7] Yeh, K.Y., Yeh, M., Mims, L. and Glass, J. (2009) Iron Feeding Induces Ferroportin 1 and Hephaestin Migration and Interaction in Rat Duodenal Epithelium. The American Journal of Physiology-Gastrointestinal and Liver Physiology, 296, 55-65. https://doi.org/10.1152/ajpgi.90298.2008

[8] Theil, E.C, Chen, H., Miranda, C., Janser, H., Elsenhans, B., Núñez, M.T., et al. (2012) Absorption of Iron from Ferritin Is Independent of Heme Iron and Ferrous Salts in Women and Rat Intestinal Segments. The Journal of Nutrition, 142, 478-483. https://doi.org/10.3945/jn.111.145854

[9] Hunt, J.R., Zito, C.A. and Johnson, L.K. (2009) Body Iron Excretion by Healthy Men and Women. American Journal of Clinical Nutrition, 89, 1792-1798.

https://doi.org/10.3945/ajcn.2009.27439

[10] Nicolas, G., Bennoun, M., Devaux, I., Beaumont, C., Grandchamp, B., Kahn, A., et al. (2001) Lack of Hepcidin Gene Expression and Severe Tissue Iron Overload in Upstream Stimulatory Factor 2 (USF2) Knockout Mice. Proceedings of the National Academy of Sciences of the United States of America, 98, 8780-8785. https://doi.org/10.1073/pnas.151179498

[11] Lin, L., Valore, E.V., Nemeth, E., Goodnough, J.B., Gabayan, V. and Ganz, T. (2007) Iron Transferrin Regulates Hepcidin Synthesis in Primary Hepatocyte Culture through Hemojuvelin and BMP2/4. Blood, 110, 2182-2189. https://doi.org/10.1182/blood-2007-04-087593

[12] Nicolas, G., Chauvet, C., Viatte, L., Danan, J.L., Bigard, X., Devaux, I., et al. (2002) the Gene Encoding the Iron Regulatory Peptide Hepcidin Is Regulated by Anemia, Hypoxia, and Inflammation. Journal of Clinical Investigation, 110, 1037-1044. https://doi.org/10.1172/JCI0215686

[13] Vokurka, M., Krijt, J., Sulc, K. and Necas, E. (2006) Hepcidin mRNA Levels in Mouse Liver Respond to Inhibition of Erythropoiesis. Physiological Research, 55, 667-674.

[14] Maliken, B.D., Nelson, J.E. and Kowdley, K.V. (2011) The Hepcidin Circuits Act: Balancing Iron and Inflammation. Hepatology, 53, 1764-1766.

https://doi.org/10.1002/hep.24267

[15] De Domenico, I., Ward, D.M. and Kaplan, J. (2007) Hepcidin Regulation: Ironing Out the Detail. Journal of Clinical Investigation, 117, 1755-1758. https://doi.org/10.1172/JCI32701

[16] National Institute of Nutrition (2010) Nutrient Requirements and Recommended Dietary Allowances for Indians. A Report of the Expert Group of the Indian Council of Medical Research. Indian Council of Medical Research. National Institute of Nutrition, Hyderabad.

[17] Camaschella, C. (2015) Iron-Deficiency Anemia. The New England Journal of Medicine, 372, 1832-1843. https://doi.org/10.1056/NEJMra1401038

[18] Danielson, J. (2004) Structure, Chemistry, and Pharmacokinetics of Intravenous Iron Agents. American Society of Nephrology, 15, S93-S98.

[19] Evans, R.W., Rafique, R., Zarea, A., Rapisarda, C., Cammack, R., Evans, P.J., et al. (2008) Nature of Non-Transferrin-Bound Iron: Studies on Iron Citrate Complexes and the Thalassemic Sera. Journal of Biological Inorganic Chemistry, 13, 57-74. https://doi.org/10.1007/s00775-007-0297-8

[20] Bhandare, B., Satyanarayana, V. and Kauser, S. (2014) Prescribing Pattern of Iron Preparations in Antenatal Women in a Tertiary Care Hospital. Journal of Interna- 
tional Medicine and Dentistry, 1, 23-27

[21] Stanley, L.S. and Michael, A. (2019) Treatment of Iron Deficiency Anemia in Adults.

https://www.uptodate.com/contents/treatment-of-iron-deficiency-anemia-in-adults

[22] Tolkien, Z., Stecher, L., Mander, A.P., Pereira, D.I. and Powell, J.J. (2015) Ferrous Sulfate Supplementation Causes Significant Gastrointestinal Side-Effects in Adults: A Systematic Review and Meta-Analysis. PLoS ONE, 10, e0117383. https://doi.org/10.1371/journal.pone.0117383

[23] Singhal, S.R., Kadian, V., Singh, S. and Ghalaut, V.S. (2015) Comparison of Various Oral Iron Salts in the Treatment of Iron Deficiency Anemia in Pregnancy. Indian Journal of Obstetrics and Gynaecology Research, 2, 155-158. https://doi.org/10.5958/2394-2754.2015.00005.3

[24] Bregman, D.B., Morris, D., Koch, T.A., He, A. and Goodnough, L.T. (2013) Hepcidin Levels Predict Nonresponsiveness to Oral Iron Therapy in Patients with Iron Deficiency Anemia. American Journal of Hematology, 88, 97-101. https://doi.org/10.1002/ajh.23354

[25] Moretti, D., Goede, J.S., Zeder, C., Jiskra, M., Chatzinakou, V., Tjalsma, H., et al. (2015) Oral Iron Supplements Increase Hepcidin and Decrease Iron Absorption from Daily or Twice-Daily Doses in Iron-Depleted Young Women. Blood, 126, 1981-1989. https://doi.org/10.1182/blood-2015-05-642223

[26] Akbarzadeh, A., Rezaei-Sadabady, R., Davaran, S., Joo, S.W., Zarghami, N., Hani-Fehpour, Y., et al. (2013) Liposome: Classification, Preparation, and Applications. Nanoscale Research Letters, 8, Article No. 102.

https://doi.org/10.1186/1556-276X-8-102

[27] Radhika, M.S., Nair, K.M., Kumar, R.H., Rao, M.V., Ravinder, P., Reddy, C.G., et al. (2011) Micronized Ferric Pyrophosphate Supplied through Extruded Rice Kernels Improves Body Iron Stores in Children: A Double-Blind, Randomized, Placebo-Controlled Midday Meal Feeding Trial in Indian School Children. The American Journal of Clinical Nutrition, 94, 1202-1210. https://doi.org/10.3945/ajen.110.007179

[28] Moretti, D., Zimmermann, M.B., Wegmuller, R., Walczyk, T., Zeder, C. and Hurrel, R.F. (2006) Iron Status and Food Matrix Strongly Affect the Relative Bioavailability of Ferric Pyrophosphate in Humans. The American Journal of Clinical Nutrition, 83, 632-638. https://doi.org/10.1093/ajcn.83.3.632

[29] Kozubek, A., Gubernator, J., Przeworska, E. and Stasiuk, M. (2000) Liposomal Drug Delivery, a Novel Approach: Plarosomes. Acta Biochimica Polonica, 47, 639-649. https://doi.org/10.18388/abp.2000_3985

[30] Xu, Z., Liu, S.Y., Wang, H.J., Gao, G.F., Yu, P. and Chang, Y.Z. (2014) Encapsulation of Iron in Liposomes Significantly Improved the Efficiency of Iron Supplementation in Strenuously Exercised Rats. Biological Trace Element Research, 162 , 181-188. https://doi.org/10.1007/s12011-014-0143-0

[31] Dra. Francesca Reig Isart (1999) Iron Absorption after Oral Administration of Different Dosage Forms. https://www.kingnature.ch/content/uploads/Estudio-CSIC-Lipofer-1999.pdf

[32] Pleşea-Condratovici, A., Pleşea-Condratovici, C., Rosoga, N. and Nedelcu, N. (2015) Efficacy and Tolerability of a Novel Food Supplement (Turbofer ${ }^{\circ}$ ) Containing Microencapsulated Iron in Liposomal Form, in Female Iron Deficiency Anaemia. Progress in Nutrition, 17, 214-219.

[33] Ding, B.M., Yi, X.Z., Li, L. and Yang, H.L. (2017) Evaluation of Iron Transport from 
Ferrous Glycinate Liposomes Using Caco-2 Cell Model. African Health Sciences, 17, 933-941. https://doi.org/10.4314/ahs.v17i3.37

[34] Parisi, F., FusĒ, F., Brunetti, M., Mazzocco, M., Berti, C. and Cetin, I. (2017) Effects of Different Regimens of Iron Supplementation on Iron Status and Pregnancy Out-Comes in a Cohort of Healthy Pregnant Women: A Randomized Control Trial. The Journal of Maternal-Fetal \& Neonatal Medicine, 30, 1787-1792. https://doi.org/10.1080/14767058.2016.1224841

[35] Blanco-Rojo, R., Pérez-Granados, A.M., Toxqui, L., González-Vizcayno, C., Delgado, M.A. and Vaquero, M.P. (2011) Efficacy of a Microencapsulated Iron Pyrophosphate-Fortified Fruit Juice: A Randomised, Double-Blind, Placebo-Controlled Study in Spanish Iron-Deficient Women. British Journal of Nutrition, 105, 1652-1659. https://doi.org/10.1017/S0007114510005490

[36] Pisani, A., Riccio, E., Sabbatini, M., Andreucci, M., Del Rio, A. and Visciano, B. (2015) Effect of Oral Liposomal Iron versus Intravenous Iron for Treatment of Iron Deficiency Anaemia in CKD Patients: A Randomized Trial. Nephrology Dialysis Transplantation, 30, 645-652. https://doi.org/10.1093/ndt/gfu357

[37] Giordano, G., Mondello, P., Tambaro, R., De Maria, M., D’Amico, F., Sticca, G., et al. (2011) Intravenous Iron Support vs Oral Liposomal Iron Support in Patients with Refractory Anemia Treated with Epo Alpha. Monocentric Prospective Study. Leukemia Research, 35, S137. https://doi.org/10.1016/S0145-2126(11)70343-5

[38] Giordano, G., Vittorio, S., D’Amico, F., Antonietta, D., De Maria, M., Nicola, P., et al. (2013) Liposomial Iron Has an Anti-Inflammatory Effect and Is Better Than Iron Sulfate in Correction of Anemia of Chronic Inflammatory Disease of Young Women. https://www.artoi.it/wp-content/uploads/2013/11/Abstract_Giordano_Giulio2.pdf 